\title{
Utility of Vocal Synchrony Measure as an Indicator of Coregulation in Adult Attachment
}

Normative aspects of infant-caregiver attachment focus on the process by which they are established were the primary focus of Bowlby's $(1969 ; 1982)$ original theory and subsequently the focus of early attachment research. But after Ainsworth and her colleagues (Ainsworth, Blehar, Waters, \& Wall, 1978) published the results of their landmark study indicating "secure," "ambivalent," and "avoidant" patterns of infant attachment, the emphasis shifted to individual differences. Much has since been learned about the nature and correlates of adult attachment patterns or "styles" (see Feeney, 1999, for a review). However, as a result of this shift in individual differences, relatively little progress has been made on the normative front. Increasingly, researchers in the fields of both infant and adult attachment are calling for more research on normative aspects of attachment (e.g., Berlin \& Cassidy, 1999; Hazan, Gur-Yaish, \& Campa, 2004). They have argued that attachment research thus far has not taken full advantage of all that Bowlby's deep and rich theory of human affectional bonding. Many basic issues remain entirely unexplored such as function and its indicators of romantic attachments.

Normative theory suggests that the function of romantic attachment includes regulation of felt security and this felt security occurs via two processes: stress buffering and coregulation (see also, Hazan et al., 2004); we will be focusing on the latter. Stress buffering refers to a process whereby romantic partners dampen each other's reactivity to stressful life events, thereby promoting stable levels of felt security even in the face of stressors. Coregulation refers to the coordination of partners' psychological and physiological states over time (Butler \& Randall, 2013; Hazan, Campa, \& Gur-Yaish, 2006). This coordination of psychological and 
physiological responses has been referred to as synchrony throughout this article. This synchrony is likely to become internalized and contribute to an "emotional sense of security" (Feldman, 2007, p. 342). The primary factor contributing to both stress buffering and coregulation is the existence of the attachment relationship rather than its quality, although attachment security level may affect the magnitude of these effects (Hazan, Campa, \& Gur-Yaish, 2006).

Work on coregulation in adult pair bonds is still in nascent stages. The strongest empirical support for coregulation comes from Feldman's (2007) studies of infant-mother attachment. She found that the infant's heart rhythms followed the deceleration or acceleration in the mother's heart rhythms. Besides, covariation of physiological systems was also in parallel with synchronous vocal behaviors including covariation of intonation and vocalization among mother-infant dyads (Feldman, Magori-Cohen, Galili, Singer, \& Louzoun, 2011). Studies similar to Feldman's are rare in the adulthood literature. Thus, the aim of this study is to examine the possibility of utilizing vocal synchrony methodology as an indicator of coregulation in romantically attached vs. stranger couples. More specifically, we assert that unlike stranger pairs, romantic partner vocalizations would be synchronous in turn-by-turn dialogues: female partners' vocal features (e.g., pitch, speech duration, and time-lag between turns) would predict male partners' vocal characteristics and vice versa in romantic partner conversations. However, we expect that no synchronous pattern in stranger partner dialogues would be observed.

\section{Attachment and Coregulation: Interwoven Emotional States between Romantic Partners}

Drawing from a combination of diverse perspectives such as psychoanalysis, evolutionary theory, ethology, and cognitive science, Bowlby (1969) proposed that 
human beings are equipped with a set of behavioral systems, each having its own functions and set-goals. He devoted most attention to the attachment behavioral system and its goals. These goals are evolutionally set to protect a newborn from the external dangers by ensuring proximity to the protective and/or caring others (called attachment figures). Bowlby (1969) described four distinct behaviors signifying attachment bond: proximity- seeking behaviors, secure base behaviors, safe haven activities, and separation protests as the building blocks of attachment behaviors. In his formulation, any sign of internal and/or external threat on the part of the infant results in the activation of the attachment system, which leads to proximity-seeking behaviors. When the "set- goal" for proximity is achieved, attachment system is deactivated.

According to Bowlby (1969), the maintenance of proximity results in feelings of security and love, whereas failing to maintain the desired level of proximity leads to anxiety, sadness, or anger. In addition to the proximity maintenance, the caregiver assumes two more responsibilities for effective functioning of the attachment bond. The attachment figure becomes (1) a "safe haven" to shelter from perceived dangers and (2) a "secure base" from which to explore. In other words, attachment figure provides emotional security which plays critical role in the daily affect regulation of infant. Infants consciously or unconsciously modulate variability in positive or negative affect states via successful affect regulation processes (Cassidy, 2008; Feldman, Weller, Sirota, \& Eidelman, 2002).

Attachment, however, is not limited to infancy and attachment relationship in infancy is between the infant and the parent is similar to pair bond in adulthood (see also, Hazan \& Shaver, 1987, 1990; Weiss, 1982). The ultimate goal of the attachment system is to achieve a sense of security by maintaining proximity to attachment 
figures. From this point of view, healthy attachment promotes effective emotion and self-regulation via different channels such as physiological and behavioral (Brennan $\&$ Shaver, 1995). By using these different channels, attachment relationships regulate the sense of security by stress buffering and coregulation/synchrony.

Although the primary factor contributing to both stress buffering and coregulation is the existence of the attachment relationship rather than its quality, stress buffering and coregulation are two different processes (Hazan, Campa, \& GurYaish, 2006). Accordingly, stress buffering refers dampening other's negative emotions when the other faced with threats. It can be seen as a unidirectional process whereby one partner down-regulates and buffers the other's negative emotions or stressful experiences. Besides, this process involves regulation of felt security before, during, or after stress exposure (Selcuk, Zayas, \& Hazan, 2010). Coregulation, however, refers to bidirectional process in which both partners influence each other's physiological and psychological states and partners' physiological and psychological states become synchronous over time (Butler \& Randall, 2013; Hazan, Campa, \& Gur-Yaish, 2006). Different from stress buffering, coregulation indicates a more general and enduring commingling of partners' psychological and physiological states and it can be observed even in relatively neutral contexts rather than positive/negative emotional contexts.

Although stress-buffering function have been well documented (see Diamond, 2001, for review), coregulation and its indicators in adult romantic relationships is largely understudied (Butler \& Randall, 2013; Sbarra \& Hazan, 2008). Indeed, the concept of coregulation is actually stemmed from animal studies and human motherinfant studies. In both human and animal infants, physical contact with early caregivers helps to organize sleep and eating behavior and the development of 
autonomic systems like the vagal system, as it has been observed in rats (Hofer, 1984) and in human babies who receive "kangaroo care" (skin-to-skin maternal contact; Feldman \& Eidelman, 2004). Thus, the attachment system, characterized by felt security, includes common properties and functions for both animals and human mother-infant pairs (Hofer, 1984; Field, 2012).

Based on these findings, the contribution of synchrony to felt security resembles the contribution of the external environment to the homeostasis of psychophysiological systems. Psychophysiological systems in humans are open to regulation from external sources. Healthy functioning and effective self-regulation (e.g., planning, organizing, and pursuing goals; adjusting behaviors to environmental demands) depends on the intactness of these regulators. For example, external lightdark cycles regulate sleep-wake cycles and circadian rhythms, and changes in lightdark cycles cause the disruption of these rhythms.

Researchers have argued that romantic partners serve a similar regulatory function (Ehlers, Frank, \& Kupfer, 1988; Hofer, 1994; Sbarra \& Hazan, 2008). When attachment is formed between two partners, their psychological and physiological systems become synchronized, and the relationship becomes a primary source of regulation for each individual. From an attachment perspective, synchrony between partners helps each partner maintain their psychological and physiological homeostatic set-point from which they can function effectively (Sbarra \& Hazan, 2008). However, synchrony does not reliably occur between strangers, suggesting that synchronous patterns are an emergent property of a close relationship and potentially, one of the indicators of an attachment relationship (Field, 2012; Hazan, Campa, \& Gur-Yaish, 2006). 
Growing body of research showed the possibility of coregulation among adult couples. For example, Butner, Diamond, and Hicks (2007) showed that partners' positive and negative affect covaried on a daily level. Another study (Saxbe \& Repetti, 2010) replicated the affect covariation findings for negative affect (though failed to do so for positive affect) and extended them by providing evidence for covariation of daily cortisol levels between spouses. When one of the spouse's cortisol level was higher than usual, the other spouse's cortisol level also tended to be higher than usual. Recently, Helm, Sbarra, and Ferrer (2014) also showed synchrony of respiratory sinus arrhythmia (RSA) in romantic couples, indicating men's and women's RSA were associated with their partners' previous RSA responses.

Detection of coregulation in romantic relationships requires different physiological responses not as closely tied to negative or positive affect as those used in prior research (Butner et al., 2007; Helm, et al., 2014; Saxbe \& Repetti, 2010). Motivated by these ideas, the current work examines whether or not vocal cues (one of the important output of emotional states) can be used as an indicator of coregulation process modulated by the presence of attachment figures.

\section{Using Vocal Cues as an Indicator of Emotional Coregulation}

In our study, a novel perspective was introduced to examine how voice features covary between romantic partners during conversation. As Darwin (1872) pointed more than a century ago, human voice is one of the principal converters of social and affective communication. Beginning from the early years, infants actively response to affect-laden vocal expressions coming from their mothers (Fernald \& Morikawa, 1993; Jaffe, et al., 2001). Thus, vocal affect seems to be a primary channel 
of emotion expression, especially during early development (Shackman \& Pollak, 2005) and continue throughout the lifespan (Scherer, 1986).

Although emotional vocal expressions are as important as facial expressions in everyday life and are recognized across cultures at rates comparable to facial expressions (Scherer \& Wallbott, 1994), vocal expressions of emotion have received far less attention from psychologists and cognitive scientists than facial expressions. Besides, previous work focusing on interpersonal associations has investigated negative or positive vocal expressions by manipulating those emotions. Past studies have mainly focused on either expression and/or recognizing emotion in an isolated manner or interactions between strangers. However, assessing affective communication of close partners via speech characteristics has a potential to provide valuable explicit information on affect communication or more specifically coregulation among adult romantic partners.

Indeed, the idea of using synchronous voice activities between romantic partners as an indicator of their coregulation comes from the nature of voice production. The human voice is the basic sound and includes the specific features of a language, such as the phonemes (i.e., vowels and consonants), grammatically significant features (i.e., pauses, intonation, and turn-taking behaviors). Previous work on human speech suggested that it is helpful to distinguish between short-term segmental aspects, which often carry linguistic information, and long-term suprasegmental aspects, which carry a mixture of paralinguistic and non-linguistic information. Nonlinguistic information of the voice can be indicators of the speaker's age and gender (O’Connor, et al., 2012), emotional state (Scherer, 1993) and, of central interest here, relationship status of interlocutors (Farley, et al., 2013). Although emotions are often also expressed in the linguistic structure and semantic 
content of speech (e.g., specific wordings), the most direct influence of emotions on speech is the way in which emotions affect suprasegmental characteristics of speech, largely through changes to the physiological mechanisms of voice production.

Speech is the product of the coordinated action of different physiological systems, such as the respiratory system and the vocal system. The respiratory system includes the lungs, trachea, thoracic cage and its associated muscles, and the diaphragm. It regulates air pressure within the lungs and drives the vocal system. The vocal system includes the vocal folds and the glottis. During the voice production, the vocal folds become close together via laryngeal muscles. As air starts to flow through the glottis, the air pressure between the vocal folds declines, causing the vocal folds to close, and the cycle repeats. The result is a periodic fluctuation in the superlaryngeal air pressure, which corresponds to a sound with a "base frequency", called the fundamental frequency (f0) and it is perceived as pitch from the listeners. Any change in the air pressure directly below the larynx (e.g. due to a change in respiratory function), or the tension and position of the vocal folds is associated with emotional states. Thus, it will affect how the vocal folds open and close, thus producing variations in the $\mathrm{f} 0$ of the sound. Such a vocal variations might be evident for certain high arousal emotions, such as anger, anxiety, and fear as well as even for subtle emotional variations.

Evolutionary models for vocal expression (Juslin \& Laukka, 2003) and empirical research on the neural substrates of speech production also suggest that $\mathrm{f} 0$ is influenced by basic physiological processes. Some of the basic vocalizations (such as signaling intimacy by using baby talk) do not have to be learned and they are innate. For example, the f0 of infant vocalizations conveys information about pain and discomfort (Young, Parsons, Stein, \& Kringelbach, 2012). These vocalizations are 
controlled by the periaqueductal gray, a structure in the brain stem that is also responsible for control of the cardiovascular system and is known to control and coordinate cardiovascular and motor responses to stress (Benarroch, 2012). In contrast, vocalizations that are the product of social learning are controlled by laryngeal motor neurons (Bass, Giland, \& Baker, 2008). Involvement of these different neural substrates in vocalizations suggests that $\mathrm{f} 0$ is probably related to the indices of physiological arousal as well as to the communication behaviors during couple interactions in everyday life. Involvement of the periaqueductal gray in controlling both vocal expression and cardiovascular responses to stress suggests that $\mathrm{f0}$ is also associated with cardiovascular variables, such as heart rate and increased or decreased blood pressure (Benarroch, 2012).

Mother-infant studies have shown that vocal synchrony predicts attachment security later (Feldman, 2003; Jaffe, et al., 2001). Reciprocal affective states between mother and infant can be evident in their synchronous vocal activities. Thus, it could be suggested that $\mathrm{f} 0$ is sensitive to emotional oscillations in daily life in adulthood and can be a successful (and indirect) indicator of emotional coregulation of adult romantic partners. Besides, considering argument that coregulation indicates a more general and enduring commingling of partners' psychological and physiological states and it can be observed even in relatively neutral contexts, emotional state of speaker in natural speech can be observed using f0 activities. In other words, from the perspective of coregulation in adulthood, $\mathrm{f} 0$ can be utilized as critical parameter of vocal covariation in conversations. If $\mathrm{f0}$ is closely linked to the emotional states, adult romantic partners f0 values should be synchronous as a manifestation of coregulation process even in relatively neutral conversations. 


\section{The Present Study}

Recent attachment research has been calling for more evidence on normative attachment process by using different levels of analysis (Hazan, Campa, \& Gur-Yaish, 2006). Studying coregulation processes at physiological level promises new theoretical explanation about the function of attachment bonds and there is need for novel measurement approaches and techniques. As proposed in this study, vocal cues of interlocutors in natural interaction can be a successful indicator of coregulation, because it has a potential to capture even subtle emotional changes in conversations.

The purpose of this study was to explore the possibility of coregulation in adulthood using the novel methodology based on the assessment of f0 and f0 variability of partners. Specifically, it was anticipated that two f0 series of close partners' conversations would be significantly correlated with each other. No such association is expected for partners who are strangers. Moreover, it was hypothesized that close partner's previous speech features (i.e., f0) in each turn would predict another partner's subsequent f0 values. Besides, this relationship would be independent from individual's previous own f0 responses. Higher correlations between the time series of $\mathrm{f} 0$ with close partner conversation are assumed to indicate synchrony between close partners. We examined directional associations between two time series and tried to show whether f0 responses were bidirectional or not.

\section{Methods}

\section{Participants}

The sample included 14 heterosexual American couples (28 participants). We excluded 2 couples from the data because they did not mention their partner as attachment figure as measured by attachment measurement. The mean age of the 
sample was $21.25(S D=1.03)$. Female participants' age ranged from 19 to $22(M=$ $21.17, S D=.94)$ and males' age ranged from 19 to $24(M=21.33, S D=1.15)$.

Couples had to meet the following criteria to be able to participate in this study: (a) they should be native English speaker; (b) they should not have a history of speech related problems that might adversely affect current utterance in conversations; and (c) they should be in a romantic relationship with the current partner for at least three months. The average duration of relationship was 16.04 months $(S D=6.17)$. The participants were recruited through the subject pool at the Cornell University Psychology Department and via flyers posted in the campus. Participants received $\$ 5$ or course credit for their participation as compensation.

\section{Procedure and Apparatus}

Two male experimenters conducted the study in the laboratory. Each subject was given a brief description of the study before the trials. Two couples were invited for each session to the laboratory at the same time. Study sessions included three stages: (1) setting the lab equipment before participants' arrival (preparation); (2) meeting with couples, presentation of informed consent forms, and switch of couples (introduction); and (3) administration of self-reported measures and debriefing.

In the preparation stage, experimenters prepared the equipment used in the study. Specifically, the microphones and volume level of earphones at the same level located in the different rooms were set. In the introduction stage, experimenters run the experiment with two couples. Specifically, two couples (4 participants) were invited to the experiment sessions at the same time. In the speech tasks, participants were asked to engage in a conversation with their romantic partner and with the other opposite sex participant in a balanced order. Conversations were about their subjective evaluations of the inkblots from the Rorschach test. To eliminate other 
non-verbal cues, couples communicated from the separate rooms. Recordings were made using an SHURE dynamic microphone in a quiet room using Audacity 1.3 recording software (Audacity Team, 2008), in stereo, and at a sampling rate of 44.1 kHz with 16-bit amplitude quantization. Two USB adapters (MXL Mic Mate Pro) were connected to the dynamic microphones and they converted voice records into computer. Partners were able to hear each other via headphones as they were talking about inkblots. They did not see each other in conversation sessions to eliminate other cues such as face, body posture etc. In the second stage of the session, one of the interlocutors was shifted to an opposite-sex stranger participant. Thus, each participant spoke with his/her close partner and a stranger in counter-balanced order.

Conversations took about ten minutes (mean duration of conversations was 7.54 minutes $(S D=4.78)$. After conversation session ended, at the closing stage, participants completed a demographic form including questions on attachment figures for a particular participants, age, relationship duration, and gender. To identify attachment figures of participants, a 10-item WHOTO scale was used (Fraley \& Davis, 1997; Hazan \& Zeifman, 1999). Example statements include, “person(s) you most like to spend time with" and "person(s) you know will always be there for you, no matter what." It allows participants to name as many attachment figures as they choose, so it is not biased toward naming only one person or one kind of person, such as a romantic partner. We used only participants who reported their romantic partner as attachment figure in further analyses. Two couples excluded from the data for further analyses. At the end of the session, they were given debriefing. 


\section{Results}

\section{Data Analytic Strategy}

A number of statistics were utilized to answer the research questions at two different levels: the session level and the turn-by-turn level. First, bivariate analyses were conducted to examine the effect of sex differences and relationship types (close vs stranger partner) in the speech features (i.e., f0) at session level. Session level analyses refer to f0 levels without considering turn-taking responses. In other words, we used mean $\mathrm{f} 0$ of each person as a variable. Then, we examined zero-order correlations between speakers. The correlation analyses provided information about the question of how two conversation partners' vocal cues (i.e., mean f0 levels) were correlated at session level. However, the correlation between two time series on the session level may not imply synchrony. It does only indicate convergence or similarity in time rather than synchronous interaction. To examine bidirectional associations between partners, one should estimate causality and reciprocity. There are sophisticated regression-based techniques that can be used to test for causality and/or bidirectionality under the specific conditions.

Second, we looked at synchrony at turn-by-turn level by using f0 mean in each turn. To understand the direction of the influence flow in social interactions, it has fundamental importance to distinguish the sender from the receiver. One of the most prominent methods to estimate the direction of the causal influence in time series analysis is the Granger Causality (Granger, 1969). This method is based on asymmetric prediction accuracies of one time series on the future of another. In detail, let two time series $\mathrm{X}_{1}$ and $\mathrm{X}_{2}$ be defined as,

$$
\begin{aligned}
& \mathrm{X}_{1(\mathrm{t})}=\Sigma \mathrm{p}_{\mathrm{j}=1} \mathrm{~A}_{11}, \mathrm{j} \mathrm{X}_{1(\mathrm{t}-\mathrm{j})}+\Sigma \mathrm{p}_{\mathrm{j}=1} \mathrm{~A}_{21}, \mathrm{j} \mathrm{X}_{2(\mathrm{t}-\mathrm{j})}+\xi_{1(\mathrm{t})}(1) \\
& \mathrm{X}_{2(\mathrm{t})}=\Sigma \mathrm{p}_{\mathrm{j}=1} \mathrm{~A}_{21}, \mathrm{j} \mathrm{X}_{1(\mathrm{t}-\mathrm{j})}+\Sigma \mathrm{p}_{\mathrm{j}=1} \mathrm{~A}_{22}, \mathrm{j} \mathrm{X}_{2(\mathrm{t}-\mathrm{j})}+\xi_{2(\mathrm{t})}(2)
\end{aligned}
$$


where $\mathrm{A}$ is the matrix containing the coefficients of the model and $\xi_{1}, \xi_{2}$ are the residuals of $X_{1}$ and $X_{2}$ respectively. A time series $X_{1}$ (in our case one of the conversation partners), is said to Granger-cause $\mathrm{X}_{2}$ (the other conversation partner) if the inclusion of past observations of $X_{1}$ reduces the prediction error of $X_{2}$ in a linear regression model of $\mathrm{X}_{2}$ and $\mathrm{X}_{1}$, as compared to a model including only the previous observations of $\mathrm{X}_{2}$. If we find $\mathrm{X}_{1}$ Granger-causes $\mathrm{X}_{2}$ and $\mathrm{X}_{2}$ Granger-causes $\mathrm{X}_{1}$, it will indicate bidirectionality at turn level analyses and will imply synchronic changes in vocal activities.

\section{Session Level Analyses}

Table 1 provides descriptive statistics for the major study variables. Initially, gender and relationship type (close vs. stranger partner) differences in vocal features, and speech related properties (i.e., turn number and speech duration in conversations) were examined. A mixed design ANOVA was run to compare the effect of gender and relationship type on mean f0 values, mean number of turn in conversation, and duration of speech.

A mixed-design ANOVA with relationship type as a within-subjects factor (close partner vs. stranger partner) and sex of the participant as a between-subject factor (male and female) was conducted on three speech features: Mean f0 values, duration of speech, and the turn number in the conversations. Mauchly's test indicated that the assumption of sphericity was accepted $(\chi 2(2)=42.40, n s)$. Confirming the sex difference, there was a significant main effect of sex on mean f0 values with a large effect size $\left(F(1,22)=990.71, p<.01, \eta^{2}=.79\right)$, indicating that female participants had higher mean $\mathrm{f} 0$ values than male participants. There was a main effect of relationship type on the turn number in the conversations $(F(1,22)=17.58, p<$ 
.001). Overall, participants took more turns in conversations with their romantic partner $(M=33.50, S D=2.05)$ than a stranger partner $(M=24.54, S D=1.31)$. Finally, both relationship type $(F(1,22)=14.41, p<.001)$ and $\operatorname{sex}(F(1,22)=5.92$, $p<.05)$ had a significant main effect on speech duration in conversations. Participants spoke longer with their romantic partners $(M=291.17$ secs., $S D=18.92)$ than stranger partner $(M=237.67$ secs., $S D=12.64)$ and female participants $(M=299.63$ secs., $S D=20.46)$ spoke longer than male participants $(M=229.21$ secs., $S D=$ 20.46). There was no significant interaction effect between within- and betweensubject factors in all analyses.

\section{Table 1}

In addition to session level differences, bivariate analyses were conducted to examine the cases in which the speakers' mean values were more similar to each other in the second part of the session. If conversation partners converge their speech features in time, two halves of f0 distances would be expected to be significantly different. To examine this, paired-sample t-test analyses were conducted to compare the two halves of the each conversation. Specifically, each individual's f0 series were divided into two equal parts and mean F0 values were obtained for each half. Paired sample t-test yielded that stranger pairs became convergent in the second part of the conversation $(t(11)=2.90, p<0.01)$ but not close partners $(t(11)=0.29, n s)$. Specifically, the distance between stranger pairs' f0 value became significantly closer in the second half of the conversation $\left(M_{1 s t ~ h a l f}=105.51 ; M_{2 n d ~ h a l f}=99.63\right)$. However, there was no significant difference between the two halves of close partners' conversation $\left(M_{1 s t \text { half }}=104.60 ; \mathrm{M}_{2 n d \text { half }}=103.75\right.$, respectively $)$. 
In sum, ANOVAs yielded only sex differences in session level mean f0 values. As expected, female participants had higher f0 values than male participants. However, mean f0 values of close partner and stranger partner conversations did not differ significantly. Moreover, paired sample t-test analyses showed that close and stranger partner conversations had different patterns. Stranger partners converged their mean F0 values in time, whereas there was no evidence for convergence among close partner conversations, indicating that they had different speech pattern in their conversations. In other words, close partners might have already converged their vocal features and thus two halves of their F0 responses did not vary. Thus, additional bivariate correlation analyses were run to investigate session level data.

\section{The associations between speech features among romantic and stranger partners}

Bivariate correlation analyses were conducted to examine the association between two time-series of data consisted of f0 values. To do this, cross-correlations between f0 series at the session level, referring f0 levels of each speaker without separating into turns were estimated. Pearson's correlation analysis was run for the each conversation pair $(N=24)$ to test the correlation between two voice waves. Table 2 depicts correlations between time-series of f0 values at session level. The average correlation coefficient was also computed for close partners $(r=.25)$ and stranger pairs $(r=.07)$.

\section{Table 2}

Although the magnitude of the correlation coefficients for close partners was relatively higher than the stranger pairs, Fisher's r-to-z transformation test yielded no significant differences between stranger pairs and close partner correlation 
coefficients $(z=0.40 ; p=0.34)$. Since Fisher's r-to-z transformation is sensitive to sample size (Preacher, 2002), this non-significant difference may be due to the small sample size.

\section{Turn Level Analyses}

Granger causality analyses were conducted on male and female participants' f0 series, reflecting voice activities while speaking with romantic partner and stranger partner separately. Although bivariate correlations show associations between time series of f0 for close partner and stranger partner conversation, Granger causality approach enables us to move beyond the detection of significant causal connections between male and female time series of $\mathrm{f} 0$ activity. It allows the examination of the direction of causality for close and stranger partners. Therefore, it can shed new light on the potential mechanisms underlying synchrony: "who affect whom with which direction".

The first step in this analysis concerns the stationary of the female and male participants' f0 series. Granger causality requires that the series have to be covariance stationary (Brooks, 2008), so an Augmented Dickey-Fuller (ADF) test has been calculated using MATLAB. For all of the series (i.e., 48 individual f0 series), the null hypothesis $\mathrm{H} 0$ of non-stationary can be rejected at a 5\% confidence level. ADF tests yielded that all the time series of $\mathrm{f0}$ under testing in this study were stationary.

The second step in this analysis concerns producing new f0 series based on the raw f0 series. Because the raw series include residuals and shocks, the number of lags to input in the model was calculated to obtain autocorrelation-free distributions. Since the Granger-causality test is very sensitive to the number of lags (i.e., turns in our case) included in the regression, the Akaike Information Criteria (AIC) have been 
used to find an appropriate number of lags in the each series. In other words, 48 unique time series (i.e., 12 male $\&$ female close partners; 12 female $\&$ male close partners; 12 male \& female stranger partners; and 12 female \& male stranger partners) were produced on the basis of ARIMA modeling. Table 3 represents the best model parameters for ARIMA modeling of F0 series. Based on Table 3, for example, f0 series of subject 1 (male speaking with his romantic partner) was produced based on the ARIMA $(4,0,1)$ modeling. Similarly, f0 series of subject 40 (female speaking with stranger male partner) was computed by using ARIMA $(2,0,3)$. The new series were used for further Granger Causality analyses. Specifically, mean score of f0 levels were computed for each turn in the conversation based on ARIMA. This way, we had 24 dyadic turn-based data and computed Granger-causality test for those data.

\section{Table 3}

The third step in this analysis concerned matching two series as close partner conversation or stranger partner conversation. For example, subject 1 (Male), as placed in Table 3, was matched with subject 25 (Female) to see whether one of the romantic partners Granger-causes to other participant's responses in f0 domain. This procedure was completed for all other alternatives (i.e., 24 conversations). After these requirements were satisfied, Granger-causality tests were computed. The results of Granger Causality were presented in Table 4.

Table 4

Granger causality analyses yielded significant results on co-occurrence of f0 activity of romantic couples, except for only one conversation highlighted in grey (see Table 4). Accordingly, the values of F statistic suggest that female f0 Granger-causes 
male f0, and similarly, male f0 level Granger-causes female f0 level, correspondingly. In other words, there was bidirectionality among romantic partners in terms of their f0 activity (Average $R^{2}=.15$ ). Specifically, past values of female voice contributed to the prediction of the present value of male voice even when past values of male own f0 values were controlled for. Similarly, past values of male voice also contributed to the estimation of the present value of female voice even when the previous values of female own f0 values were taken into account. As previous work on EEG signals using Granger-causality analysis suggested (e.g., Barrett, et al., 2012), bidirectionality in Granger-causality possibly indicates a cyclical process and based on this argument, these findings suggest synchronous patterns between close partner conversations.

As in the case of romantic partners' analyses, two hypotheses were tested for stranger partner conversations: (a) whether there is causality from earlier male f0 to later female $\mathrm{f}$, and (b) whether there is causality from earlier female f0 to later male f0. Contrary to the findings of romantic partners, Granger-causality analyses for the stranger partner conversations yielded a different pattern. There was only a significant causality from earlier female f0 levels to later male f0 levels (except for two cases highlighted in grey) (Average $R^{2}=.17$ ). In other words, stranger female participants' earlier f0 Granger-caused stranger male participants' subsequent f0 values in their conversations. There was no Granger-causality from past values of male f0 to subsequent values of female f0. In short, there was Granger-causality from female to male only in stranger partner conversations indicating that female participants' previous f0 responses Granger-caused male participants' f0 responses subsequently. However, male participants' f0 responses had no impact on female participants' subsequent f0 responses. 
Consistent with the results of bivariate correlation analyses, Granger-causality analyses signified that romantic partners, but not stranger dyads, influence each other's speech features synchronically. In other words, we observed bidirectional f0 covariation in turn-based conversations. As a result, in conversation with close partner who is reported as attachment figure, individuals' f0 level has been associated with their romantic partners' previous voice features in cyclical process. In contrast, stranger male participants' fo level was associated with a stranger female conversation partner, but female participants' f0 level was not predicted by stranger male participants' previous f0 values. This pattern suggests a convergence of male stranger participants toward female stranger participants.

\section{Discussion}

The results of this study support the idea that vocal synchrony measure can be utilized to measure coregulation among romantically attached partners. As a new perspective, one of the important features of speech (i.e., f0) was assessed in dyadic conversations and the question of how f0 covaries between partners during conversation episodes was examined. Session level analyses indicated that turn taking behaviors were more frequent in close partner conversations than the stranger partner condition. Moreover, as would be expected, individuals spoke with their romantic partners longer than stranger partner since they have common bases, shared experiences etc. to engage in a longer duration of talk. Session level analyses also showed that mean f0 values in stranger partner conversation, but not close partner conversation became convergent in the second part. Specifically, the distance between stranger pairs' f0 values was significantly closer in the second half of the conversation. This finding was consistent with the prediction of communication 
accommodation theory indicating that people have a tendency to converge their features of speech such as the use of paralanguage, pronunciation, pause and utterance lengths, vocal intensities, nonverbal behaviors, and intimacy of self- disclosures (Giles \& Ogay, 2007). Another explanation about why stranger partners converged their $\mathrm{f} 0$ responses in the second half of the conversation can be explained by Chartrand and Bargh's (1999) finding about the perception-behavior link. They suggested that the act of observing another's behavior increases the likelihood of the observer's engaging in that behavior in time. Thus, convergence between the strangers' talk in the second half of their conversation can be interpreted as a tendency to mimic conversation partner.

There are different ways in which partners' emotions can be synchronous and it can be produced either an in-phase (changes in similar directions or positive correlation) or anti-phase (changes in opposite directions or negative correlation) pattern (Butler, 2011). The results of the correlation analyses suggested that intimate partners produced in-phase pattern of synchrony. The changes in $\mathrm{f} 0$ responses were similar and positively correlated. According to Butler (2011), one of the specific forms of emotional coordination can be morphostatic pattern, in which an individual's emotions at one time are used to predict their partner's emotions at a later time, while controlling for the first individual's prior emotions. This form of coordination, in which partner's emotions vary concurrently, was assessed as synchrony or coregulation indicator in this study. Supporting this, initially, session level correlations were computed for two series. Although Fisher's r-to-z transformation test yielded no significant differences between mean of stranger pairs and close partner correlation coefficients $(\mathrm{z}=0.40 ; \mathrm{p}=0.34)$, this nonsignificant difference seems to stem from the small sample size for this analysis. 
Correlation analyses, however, do not refer causal or bidirectional associations, which is indicator of synchronous f0 responses. Granger-causality analyses provided further understandings about the nature of communication patterns of interaction partners. These analyses yielded that close partner f0 responses were bidirectional. In other words, in close partner conversation, previous female f0 responses Granger-caused to subsequent male f0 responses and vice versa (see Table 4). Granger-causality analyses for stranger partner conversations, however, yielded unidirectional relationships between male and female partners. Accordingly, only female f0 responses predicted subsequent male f0 responses, but male participants' f0 responses did not predict later female participants' f0 levels. To interpret these findings, it is important to keep in mind that bidirectional relationships in close partner f0 responses implicitly refer to coregulation process.

A majority of past studies on emotional coordination or synchrony between romantic partners have shown that partners' emotions are positively correlated - their emotions change in unison (in-phase coordination) (e.g., Butner et al., 2007; Saxbe \& Repetti, 2010; Schoebi, 2008). The concept of synchrony or coregulation possesses have critical implications in understanding the underlying mechanisms of attachment formation. As shown in previous work (e.g., Reite \& Field, 1985; Jaffe et al., 2001), infants and their mothers show considerable coherence in responses (attunement) at both biological (e.g., heart rate synchrony) and behavioral levels (e.g., vocal synchrony) within the attachment relationship. Researchers have suggested that romantic partners may serve similar regulatory function (Sbarra \& Hazan, 2008). Once attachment is formed between romantic partners, their physiological and behavioral systems are synchronized to each other and their relationship provides regulatory source to each individual. From this perspective, synchronized systems 
support partners' psychological and physiological homeostatic set-point from which they can function effectively (Sbarra \& Hazan, 2008). Similarly, the manifestation of these synchronized systems is parallel with infant-mother studies showing reciprocal associations of behavioral or physiological systems (Feldman, 2007; Feldman, et al., 2011). The findings of reciprocal influences of close partners in conversation are consistent with this idea. In the conversation, partners showed reciprocal responses at vocal level and this bidirectionality may be due to their attuned prosody over time.

The finding on the bidirectional associations of $\mathrm{f} 0$ responses between romantic partners also highlights the differences between coregulation and stress buffering function of attachment relationships. Coregulation is a defining feature of normative attachment, whereas stress buffering is a necessary but not a sufficient element of clear-cut attachment relationship (Sbarra \& Hazan, 2008). Stress buffering has been described as a unidirectional mechanism whereby one partner down-regulates the other partner's stress reactivity. Coregulation, however, is a bidirectional mechanism whereby both partners influence each other's physiological and psychological states (Selcuk, Zayas, \& Hazan, 2010) as what Granger-causality analyses showed. Therefore, synchrony in $\mathrm{f} 0$ responses indexing coregulation can be seen as a vocal marker of attachment relationships. If we manipulated mood state of participants and then observed their vocal responses, we might find additional vocal evidences in stress-buffering process.

Another important finding from Granger-causality analyses is that previous f0 responses of female participants predicted subsequent f0 responses of males in stranger partner conversation. Different from close partner conversation, f0 responses are unidirectional in stranger partner conversation. In other words, male participants seem to mimic female participants in terms of the f0 responses. This finding has two 
important implications. First, individuals seem to have a sustained synchrony with their close partner but not stranger partners. Second, only men, but not women initiating a conversation with the opposite sex stranger partners have a tendency to mimic their vocalizations with the female partner.

The observed sex difference seems to be inconsistent with the previous work in communication accommodation. For example, Stupka (2011) showed that female participants accommodate their speech style more frequently than male participants. Accommodation was calculated using the incidence of the conversational indicators. In that study, individual accommodation was determined via the adherence to or deviation from gender stereotypical indicators including verbal content of communication. This finding suggests sex differences in vocal accommodation might be due to social or affiliative motives during social interactions. Sex differences in social experience and social reinforcement render women more sensitive to verbal content in vocal communication than men. However, Stupka's (2011) study did not focus on the voice related features such as intonation or vocalizations. Most of the previous research has focused on the role of deliberative and conscious processes on conversation style and has implicitly or explicitly assumed that such communication strategies are driven by deliberative processes (e.g., Cohen, 2009; Namy, Nygaard, \& Sauerteig, 2002).

Investigating accommodation using relatively unconscious cues, such as physiologically moderated cues may provide different information about mating behaviors of males and females. Consistently, previous research focusing on the impact of relationship status on mimicking (i.e., face rubbing) opposite sex indicated that male participants showed more mimicry than female participants (Karremans \& Verwijmeren, 2008). It should be noted that these results were obtained for 
participants who had romantic relationship currently. Similar to Karremans and Verwijmeren's (2008) study, the results of the current study indicated that male participants converge their voice features to stranger female participants' rhythms.

The present finding about female f0 responses predicted later male f0 responses also partially consistent with evolutionary perspective, suggesting that male of various species change their behavior if they try to find or keep a mate. This can be manifested in different ways: males can align their non-linguistic behaviors such as intonation with the members of opposite sex for the sake of their mating goals (Pickering \& Garrod, 2004). For example, Coyle and Kaschak (2012) showed that male participants had a tendency to mimic female participants' sentence structure, which is unintentional changes in language usage however; female participants do not adopt linguistic behavior of male participants. Similarly, male participants had a tendency to mimic vocal features of both intimate and stranger female partners in our study.

This study offers a new methodology to extend previous literature on interconnectedness of physiological systems by using vocal cues. It was proposed that using vocal cues could be used in examining cross-partner associations at vocal level. Based on the linguistic alignment and prosody research, it was assumed that physiological states directly influence voice features such as f0 responses. To show bidirectional, cyclic relationship in vocal responses, a series of statistical modeling were used and results provided information regarding vocal responses can be used as one of the reliable markers of coregulation. Because this is the first empirical examination of vocal synchrony within romantic partners, it is difficult to offer firm conclusions about their implications for couple functioning but this research direction 
is promising regarding reliable markers of attachment relationships using vocal features.

Future research should employ more sophisticated research designs to better understand the underlying mechanisms in vocal behaviors by examining different types of conversation contents, such as the discussion of problematic or conflictual relationship issues that may elicit negative affect or happy memories promoting positive affect. Couples may show divergent vocal patterns in the conversations under negative or positive moods. Testing such processes can help generalize the idea of vocal markers of coregulation and their implications for couple functioning in different settings including friendship and coworkers.

Second, further studies should also compare physiological responses and vocal behaviors concurrently during the couple interactions. Thus, the correlates or multiple indicators of vocal behaviors as markers of coregulation can be systematically investigated. Besides, observing synchrony in the other communication parameters, such as facial cues, body movements or posture can be very informative to better understand the normative attachment behaviors at multiple levels and the process of attachment-in-the-making in adult relationships. 


\section{References}

Ainsworth, M. D. S., Blehar, M. C., Waters, E., \& Wall, S. (1978). Patterns of Attachment: A Psychological Study of the Strange Situation. Hillsdale, NJ: Erlbaum.

Audacity Team (2012): Audacity (Version 1.3.4-beta) [Computer program]. Retrieved May 5, 2012, from http://audacity.sourceforge.net/

Barrett, A. B., Murphy, M., Bruno, M. A., Noirhomme, Q., Boly, M., Laureys, S., \& Seth, A. K., (2012). Granger causality analysis of steady-state electroencephalographic signals during propofol-induced anaesthesia. PLoS One 7, e29072. doi:10.1371/journal.pone.0029072.

Bass, A. H., Gilland, E., Baker, R. (2008). Evolutionary origins for social vocalization in a vertebrate hindbrain-spinal compartment. Science, 321, 417-421.

Benarroch, E., E. (2012). Periaqueductal gray: an interface for behavioral control. Neurology, 78, 210-217.

Berlin, L. J., \& Cassidy, J. (1999). Relations among relationships: Contributions from attachment theory and research. In J. Cassidy \& P. R. Shaver (Eds.), The handbook of attachment theory and research (pp. 688-712). New York: Guilford Publications.

Bowlby, J. (1969). Attachment and loss. Vol. I: Attachment. London: Penguin Books.

Bowlby, J. (1982). Attachment and loss. Vol. I: Attachment (2nd Ed.). New York: Basic Books 
Brennan, K. A., \& Shaver, P. R. (1995). Dimensions of adult attachment, affect regulation, and romantic relationship functioning. Personality and Social Psychology Bulletin, 21, 267-283.

Brooks, C. (2008). Introductory Econometrics for Finance. Cambridge Book: London.

Butler, E., A. \& Randall, A., K. (2013). Emotional coregulation in close relationships. Emotion Review, 5, 202-210.

Butler, E., A. (2011). Temporal interpersonal emotion systems: The "TIES" that form relationships. Personality and Social Psychology Review, 15, 367-393.

Butner, J., Diamond, L. M., \& Hicks, A. M. (2007). Attachment style and two forms of emotion coregulation between romantic partners. Personal Relationships, $14,431-455$.

Cassidy, J. (2008). The nature of the child's ties. In J. Cassidy \& P. R. Shaver (Eds.), Handbook of attachment: Theory, research, and clinical applications (2nd ed.). New York: Guilford Publications.

Chartrand, T. L., \& Bargh, J. A. (1999). The chameleon effect: The perceptionbehavior link and social interaction. Journal of Personality and Social Psychology, 76, 893-910.

Cohen, S., J. (2009). Gender Differences in Speech Temporal Patterns Detected Using Lagged Co-occurrence Text-Analysis of Personal Narratives. Journal of Psycholinguistic Research, 38, 111-127. 
Coyle, J., M,, \& Kaschak, M., P. (2012). Female Fertility Affects Men's Linguistic Choices. PLoS ONE, 7, e27971. doi:10.1371/journal.pone.0027971.

Darwin, C. (1872). The expression of the emotions in man and animals. London: John Murray.

Diamond, L. M. (2001). Contributions of psychophysiology to research on adult attachment: Review and recommendations. Personality and Social Psychology Review, 5, 276-295.

Ehlers, C. L., Frank, E., \& Kupfer, D. J. (1988). Social zeitgebers and biological rhythms. Archives of General Psychiatry, 45, 948-952

Farley, S., D., Hughes, S., M., LaFayette, J., N. (2013). People will know we are in love: evidence of differences between vocal samples directed toward lovers and friends. Journal of Nonverbal Behavior, 37, 123 -129.

Feeney, J.A. (1999). Adult romantic attachment and couple relationships. In J. Cassidy \& P. Shaver (Eds.), Handbook of attachment theory and research. pp. 355-377. New York:Guilford Press.

Feldman, R., \& Eidelman, A., I. (2004). Parent-infant synchrony and the socialemotional development of triplets. Developmental Psychology, 40, 11331147.

Feldman, R. (2003). Infant-mother and infant-father synchrony: The coregulation of positive arousal. Infant Mental Health Journal 24, 1-23. 
Feldman, R. (2007). Parent-infant synchrony and the construction of shared timing: Physiological precursors, developmental outcomes, and risk conditions. Journal of Child Psychology and Psychiatry, 48, 329-354.

Feldman, R., Magori-Cohen, R., Galili, G., Singer, M., Louzoun, Y. (2011). Mother and infant coordinate heart rhythms through episodes of interaction synchrony. Infant Behavior and Development, 34, 569-577.

Feldman, R., Weller, A., Sirota, L., \& Eidelman, A. I. (2002). Skin-to-skin contact (Kangaroo Care) promotes self-regulation in premature infants: Sleep-wake cyclicity, arousal modulation, and sustained exploration. Developmental Psychology, 38, 194-207.

Fernald, A. \& Morikawa, H. (1993). Common themes and cultural variations in Japanese and American mothers' speech to infants. Child Development, 64, 637-656.

Field, T. (2012). Relationships as regulators. Psychology, 3, 467-479.

Fraley, R. C., \& Davis, K. E. (1997). Attachment formation and transfer in young adults' close friendships and romantic relationships. Personal Relationships, 4, 131-144.

Giles, H., \& Ogay, T. (2007). Communication accommodation theory. In B. B. Whaley \& W. Samter (Eds.), Explaining communication: Contemporary theories and exemplars (pp. 293-310). Mahwah, NJ: Lawrence Erlbaum.

Granger, C. W. J. (1969). Investigating Causal Relations by Econometric Models and Cross-spectral Methods. Econometrica, 37, 424-438. 
Hazan, C., \& Shaver, P. (1987). Romantic love conceptualized as an attachment process. Journal of Personality and Social Psychology, 52, 511-524.

Hazan, C., \& Shaver, P.R. (1990). Love and work: An attachment-theoretical perspective. Journal of Personality and Social Psychology, 59, 270-280.

Hazan, C. \& Zeifman, D. (1999). Pair bonds as attachments: Evaluating the evidence. In J.Cassidy \& P.R. Shaver (Eds.) Handbook of Attachment Theory and Research.

Hazan, C., Gur-Yaish, N., \& Campa, M. (2006). What does it mean to be attached? In W.S. Rholes \& J.A. Simpson (Eds.), Adult attachment: Theory, research, and clinical implications (pp. 55-85). New York: Guilford Press.

Helm, J., Sbarra, D.A., \& Ferrer, E. (2014). Coregulation of respiratory sinus arrhythmia in adult romantic partners. Emotion, 14, 522-531.

Hofer, M., A. (1984). Relationships as regulators: A psychobiological perspective on bereavement. Psychosomatic Medicine, 46, 183-197

Hofer, M., A. (1994). Hidden regulators in attachment, separation, and loss. Monographs of the Society for Research in Child Development, 59, 250 283.

Jaffe, J., Beebe, B., Feldstein, S., Crown, C. L., \& Jasnow, M. D. (2001). Rhythms of dialogue in infancy. In W. D. Overton (Ed.), Monographs of the Society for Research in Child Development, 265, Volume 2. 
Juslin, P., N., \& Laukka, P. (2003). Communication of emotions in vocal expression and music performance: Different channels, same code? Psychological Bulletin, 129, 770-814.

Karremans, J., C., \& Verwijmeren, T. (2008). Mimicking Attractive Opposite-Sex Others: The Role of Romantic Relationship Status. Personality and Social Psychology Bulletin, 34, 939-950.

Namy, L., L., Nygaard, L., C., \& Sauerteig, D. (2002). Gender Differences in Vocal Accommodation: The Role of Perception. Journal of Language and Social Psychology, 21, 422-432.

O’Connor, J.J.M.,Feinberg, D.R., Fraccaro, P.J., Borak, D.J. Tigue, C.C., Re., D.E., Jones, B.C., Little, A.C., \& Tiddeman, B. (2012). Female preferences for male vocal and facial masculinity in videos. Ethology, 118, 321-330.

Pickering M.J., Garrod S. (2004) Toward a Mechanistic Psychology of Dialogue. Behavioral and Brain Sciences, 27, 169-225.

Preacher, K. J. (2002, May). Calculation for the test of the difference between two independent correlation coefficients [Computer software]. Available from http://quantpsy.org.

Reite, M., \& Field, T. (1985). The Psychobiology of attachment and separation. Orlando: Academic Press.

Saxbe, D., \& Repetti, R. L. (2010). For better or worse? Coregulation of couples' cortisol levels and mood states. Journal of Personality and Social Psychology, 98, 92-103. 
Sbarra, D. A., \& Hazan, C. (2008). Coregulation, dysregulation, self-regulation: An integrative analysis and empirical agenda for understanding adult attachment, separation, loss, and recovery. Personality and Social Psychology Review, $12,141-167$.

Scherer, K. R., \& Wallbott H. G. (1994). Evidence for universality and cultural variation of differential emotion response patterning. Journal of Personality and Social Psychology. 66, 310-328.

Scherer, K. R. (1986). Vocal affect expression: A review and a model for future research. Psychological Bulletin, 99, 143- 165.

Scherer, K. R. (1993). Interpersonal expectations, social influence, and emotion transfer. In P. D. Blanck (Ed.), Interpersonal expectations: Theory, research, and application (pp. 316-336). Cambridge, England: Cambridge University Press.

Schoebi, D. (2008). The Coregulation of Daily Affect in Marital Relationships. Journal of Family Psychology, 22, 595 - 604.

Selcuk, E., Zayas, V., \& Hazan, C. (2010). Beyond Satisfaction: The Role of Attachment in Marital Functioning. Journal of Family Theory \& Review, 2, $258-279$.

Shackman, J., S., \& Pollak, S., D. (2005). Experimental influences on multimodal perception of emotion. Child Development, 76, 1116-1126.

Stupka, R. (2011). Communication Accommodation in Mixed Gender Dyads. Communication Research, 19, 479-492. 
Weiss, R. S. (1982). Attachment in adult life. In C. M. Parkes \& J. Stevenson-Hinde (Eds.), The place of attachment in human behavior (pp. 171-184). New York: Basic Books.

Young, K., S., Parsons, C., E., Stein, A., \& Kringelbach, M., L. (2012). Interpreting infant vocal distress: The ameliorative effect of musical training in depression. Emotion, 12, 1200-1205. 
Table 1. Descriptives for study variables

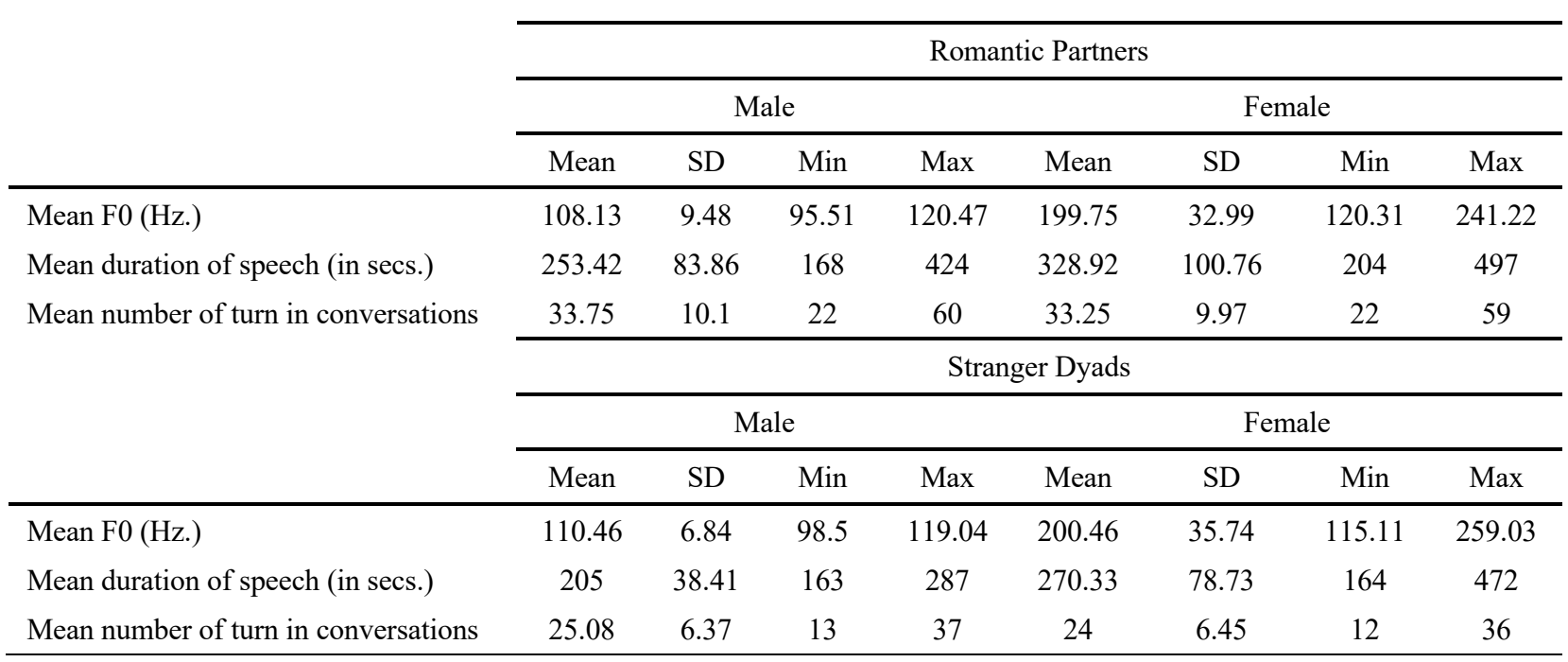


Table 2. Cross-correlations for each dyad's conversation

\begin{tabular}{|c|c|c|c|c|c|c|c|c|c|c|c|c|}
\hline & $101 \mathrm{~F}$ & $102 \mathrm{~F}$ & $103 \mathrm{~F}$ & $104 \mathrm{~F}$ & $105 \mathrm{~F}$ & $106 \mathrm{~F}$ & $107 \mathrm{~F}$ & $108 \mathrm{~F}$ & $109 \mathrm{~F}$ & $110 \mathrm{~F}$ & $111 \mathrm{~F}$ & $112 \mathrm{~F}$ \\
\hline $101 \mathrm{M}$ & 0.22 & 0.06 & & & & & & & & & & \\
\hline $102 \mathrm{M}$ & 0.02 & 0.18 & & & & & & & & & & \\
\hline $103 \mathrm{M}$ & & & 0.25 & 0.10 & & & & & & & & \\
\hline $104 \mathrm{M}$ & & & 0.07 & 0.21 & & & & & & & & \\
\hline $105 \mathrm{M}$ & & & & & 0.32 & 0.05 & & & & & & \\
\hline $106 \mathrm{M}$ & & & & & 0.12 & 0.23 & & & & & & \\
\hline $107 \mathrm{M}$ & & & & & & & 0.36 & 0.02 & & & & \\
\hline $108 \mathrm{M}$ & & & & & & & 0.03 & 0.19 & & & & \\
\hline $109 \mathrm{M}$ & & & & & & & & & 0.27 & 0.04 & & \\
\hline $110 \mathrm{M}$ & & & & & & & & & 0.12 & 0.34 & & \\
\hline $111 \mathrm{M}$ & & & & & & & & & & & 0.25 & 0.08 \\
\hline $112 \mathrm{M}$ & & & & & & & & & & & 0.10 & 0.20 \\
\hline $\begin{array}{l}\text { Mean r Close } \\
\text { Relationships }\end{array}$ & 0.25 & & & & & & & & & & & \\
\hline Mean r Stranger Pairs & 0.07 & & & & & & & & & & & \\
\hline
\end{tabular}
Note: $\mathrm{F}=$ Female participant; $\mathrm{M}=$ Male participant; Correlations between romantic partners were highlighted in grey. 
Table 3. ARIMA modeling parameter estimates

\begin{tabular}{|c|c|c|c|c|c|c|c|c|c|c|c|c|c|}
\hline \multicolumn{2}{|l|}{ Subject \# } & 1 & 2 & 3 & 4 & 5 & 6 & 7 & 8 & 9 & 10 & 11 & 12 \\
\hline \multirow{3}{*}{ 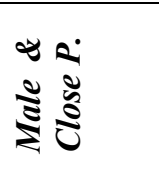 } & $\mathbf{p}$ & 4 & 2 & 3 & 4 & 8 & 2 & 5 & 2 & 1 & 4 & 3 & 2 \\
\hline & d & 0 & 0 & 1 & 0 & 0 & 0 & 1 & 0 & 1 & 0 & 0 & 0 \\
\hline & $\mathbf{q}$ & 1 & 3 & 4 & 1 & 6 & 3 & 5 & 1 & 8 & 1 & 1 & 6 \\
\hline \multicolumn{2}{|c|}{ Subject \# } & 13 & 14 & 15 & 16 & 17 & 18 & 19 & 20 & 21 & 22 & 23 & 24 \\
\hline \multirow{3}{*}{ 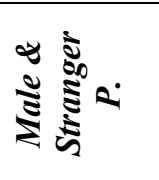 } & $\mathbf{p}$ & 1 & 2 & 3 & 2 & 3 & 3 & 1 & 2 & 2 & 2 & 4 & 2 \\
\hline & d & 1 & 1 & 1 & 0 & 0 & 0 & 1 & 0 & 0 & 1 & 0 & 0 \\
\hline & $\mathbf{q}$ & 1 & 2 & 5 & 3 & 1 & 1 & 7 & 7 & 1 & 3 & 1 & 1 \\
\hline \multicolumn{2}{|c|}{ Subject \# } & 25 & 26 & 27 & 28 & 29 & 30 & 31 & 32 & 33 & 34 & 35 & 36 \\
\hline \multirow{3}{*}{ 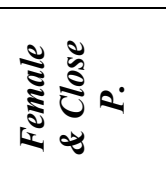 } & $\mathbf{p}$ & 2 & 1 & 2 & 2 & 4 & 7 & 2 & 4 & 2 & 2 & 3 & 2 \\
\hline & d & 1 & 1 & 0 & 0 & 1 & 1 & 1 & 0 & 0 & 0 & 0 & 1 \\
\hline & $\mathbf{q}$ & 5 & 1 & 1 & 1 & 4 & 2 & 4 & 1 & 1 & 2 & 1 & 3 \\
\hline \multicolumn{2}{|c|}{ Subject \# } & 37 & 38 & 39 & 40 & 41 & 42 & 43 & 44 & 45 & 46 & 47 & 48 \\
\hline \multirow{3}{*}{ 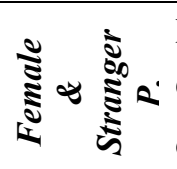 } & $\mathbf{p}$ & 2 & 1 & 3 & 2 & 3 & 3 & 2 & 2 & 2 & 3 & 2 & 2 \\
\hline & & 0 & 1 & 1 & 0 & 0 & 0 & 0 & 0 & 0 & 0 & 0 & 0 \\
\hline & $\mathbf{q}$ & 1 & 7 & 5 & 3 & 1 & 1 & 1 & 1 & 3 & 1 & 6 & 3 \\
\hline
\end{tabular}


Table 4. Testing Granger-causality of mean score f0 at each turn toward null hypothesis

\begin{tabular}{|c|c|c|c|c|c|c|c|c|c|}
\hline & & $\begin{array}{c}\text { Null } \\
\text { Hypothesis }\end{array}$ & F-Statistics & $\mathbf{R}^{2}$ & & & $\begin{array}{c}\text { Null } \\
\text { Hypothesis }\end{array}$ & F-Statistics & $\mathbf{R}^{2}$ \\
\hline \multirow{25}{*}{ 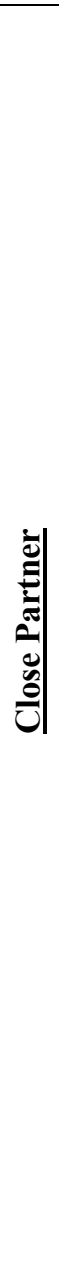 } & \multirow{2}{*}{$\begin{array}{c}\text { Pair } 1 \\
\text { Obs }=5216\end{array}$} & $\mathrm{~F} \neq>\mathrm{M}$ & $4.58^{* *}$ & \multirow{2}{*}{.08} & & \multirow{2}{*}{$\begin{array}{c}\text { Pair } 13 \\
\text { Obs }=3213\end{array}$} & $\mathrm{~F} \neq>\mathrm{M}$ & 1.09 & \multirow{2}{*}{.02} \\
\hline & & $\mathrm{M} \neq>\mathrm{F}$ & $3.29^{*}$ & & & & $\mathrm{M} \neq>\mathrm{F}$ & 0.63 & \\
\hline & \multirow{2}{*}{$\begin{array}{c}\text { Pair } 2 \\
\text { Obs }=5944\end{array}$} & $\mathrm{~F} \neq>\mathrm{M}$ & $6.23^{* *}$ & \multirow{2}{*}{.12} & & \multirow{2}{*}{$\begin{array}{c}\text { Pair } 14 \\
\text { Obs }=2439\end{array}$} & $\mathrm{~F} \neq>\mathrm{M}$ & $4.11^{*}$ & \multirow{2}{*}{.14} \\
\hline & & $\mathrm{M} \neq>\mathrm{F}$ & $3.22^{*}$ & & & & $\mathrm{M} \neq>\mathrm{F}$ & 1.51 & \\
\hline & \multirow{2}{*}{$\begin{array}{c}\text { Pair } 3 \\
\text { Obs }=1930\end{array}$} & $\mathrm{~F} \neq>\mathrm{M}$ & $3.79^{*}$ & \multirow{2}{*}{.11} & & \multirow{2}{*}{$\begin{array}{c}\text { Pair } 15 \\
\text { Obs }=3186\end{array}$} & $\mathrm{~F} \neq>\mathrm{M}$ & $4.99^{* *}$ & \multirow{2}{*}{.25} \\
\hline & & $\mathrm{M} \neq>\mathrm{F}$ & $2.36^{*}$ & & & & $\mathrm{M} \neq>\mathrm{F}$ & 0.28 & \\
\hline & \multirow{2}{*}{$\begin{array}{c}\text { Pair } 4 \\
\text { Obs }=3173\end{array}$} & $\mathrm{~F} \neq>\mathrm{M}$ & $5.75^{* *}$ & \multirow{2}{*}{.13} & & \multirow{2}{*}{$\begin{array}{c}\text { Pair } 16 \\
\text { Obs }=474\end{array}$} & $\mathrm{~F} \neq>\mathrm{M}$ & 2.13 & \multirow{2}{*}{.13} \\
\hline & & $\mathrm{M} \neq>\mathrm{F}$ & $4.19^{* *}$ & & & & $\mathrm{M} \neq>\mathrm{F}$ & 0.45 & \\
\hline & \multirow{2}{*}{$\begin{array}{c}\text { Pair 5 } \\
\text { Obs=3861 }\end{array}$} & $\mathrm{F} \neq>\mathrm{M}$ & $4.01^{*}$ & \multirow{2}{*}{.11} & \multirow{8}{*}{ : } & \multirow{2}{*}{$\begin{array}{c}\text { Pair } 17 \\
\text { Obs }=2955\end{array}$} & $\mathrm{~F} \neq>\mathrm{M}$ & $4.80^{* *}$ & \multirow{2}{*}{.28} \\
\hline & & $\mathrm{M} \neq>\mathrm{F}$ & $3.12^{*}$ & & & & $\mathrm{M} \neq>\mathrm{F}$ & 0.41 & \\
\hline & \multirow{2}{*}{$\begin{array}{c}\text { Pair } 6 \\
\text { Obs }=3443\end{array}$} & $\mathrm{~F} \neq>\mathrm{M}$ & 0.50 & \multirow{2}{*}{.08} & & \multirow{2}{*}{$\begin{array}{c}\text { Pair } 18 \\
\text { Obs }=980\end{array}$} & $\mathrm{~F} \neq>\mathrm{M}$ & $3.22^{*}$ & \multirow{2}{*}{.11} \\
\hline & & $\mathrm{M} \neq>\mathrm{F}$ & 1.85 & & & & $\mathrm{M} \neq>\mathrm{F}$ & 1.18 & \\
\hline & \multirow{2}{*}{$\begin{array}{c}\text { Pair } 7 \\
\text { Obs }=2202\end{array}$} & $\mathrm{~F} \neq>\mathrm{M}$ & $4.42^{* *}$ & \multirow{2}{*}{.24} & & \multirow{2}{*}{$\begin{array}{c}\text { Pair } 19 \\
\text { Obs }=1838\end{array}$} & $\mathrm{~F} \neq>\mathrm{M}$ & $4.53^{* *}$ & \multirow{2}{*}{.18} \\
\hline & & $\mathrm{M} \neq>\mathrm{F}$ & $3.71^{*}$ & & & & $\mathrm{M} \neq>\mathrm{F}$ & 1.19 & \\
\hline & \multirow{2}{*}{$\begin{array}{c}\text { Pair } 8 \\
\text { Obs }=2181\end{array}$} & $\mathrm{~F} \neq>\mathrm{M}$ & $4.14^{*}$ & 11 & & Pair 20 & $\mathrm{~F} \neq>\mathrm{M}$ & $3.44^{*}$ & 22 \\
\hline & & $\mathrm{M} \neq>\mathrm{F}$ & $2.57^{*}$ & .11 & & Obs $=836$ & $\mathrm{M} \neq>\mathrm{F}$ & 0.39 & .22 \\
\hline & Pair 9 & $\mathrm{~F} \neq>\mathrm{M}$ & $2.55^{*}$ & 19 & & Pair 21 & $\mathrm{~F} \neq>\mathrm{M}$ & $2.96^{\dagger}$ & 19 \\
\hline & Obs $=3073$ & $\mathrm{M} \neq>\mathrm{F}$ & $4.14^{*}$ & .19 & & Obs $=2778$ & $\mathrm{M} \neq>\mathrm{F}$ & 1.01 & .19 \\
\hline & Pair 10 & $\mathrm{~F} \neq>\mathrm{M}$ & $6.17^{* *}$ & 13 & & Pair 22 & $\mathrm{~F} \neq>\mathrm{M}$ & $5.03^{* *}$ & 11 \\
\hline & Obs $=2433$ & $\mathrm{M} \neq>\mathrm{F}$ & $3.78^{*}$ & & & Obs $=1027$ & $\mathrm{M} \neq>\mathrm{F}$ & 1.15 & .11 \\
\hline & Pair 11 & $\mathrm{~F} \neq>\mathrm{M}$ & $4.19^{* *}$ & 26 & & Pair 23 & $\mathrm{~F} \neq>\mathrm{M}$ & $4.77^{*}$ & 29 \\
\hline & Obs $=1813$ & $\mathrm{M} \neq>\mathrm{F}$ & $4.67^{* *}$ & .20 & & Obs $=873$ & $\mathrm{M} \neq>\mathrm{F}$ & 0.98 & .29 \\
\hline & Pair 12 & $\mathrm{~F} \neq>\mathrm{M}$ & $2.54^{*}$ & 21 & & Pair 24 & $\mathrm{~F} \neq>\mathrm{M}$ & $3.52^{*}$ & 16 \\
\hline & Obs $=3423$ & $\mathrm{M} \neq>\mathrm{F}$ & $3.21^{*}$ & .21 & & Obs $=1217$ & $\mathrm{M} \neq>\mathrm{F}$ & 1.89 & .10 \\
\hline & & & Mean $\mathbf{R}^{2}$ & .15 & & & & Mean $\mathbf{R}^{2}$ & .17 \\
\hline
\end{tabular}

$* * \mathrm{p}<.01 ; * \mathrm{p}<.05 ; \dagger \mathrm{p}<.07$

Obs $=$ Number of observation (turn in conversations) in f0 time series 